\title{
Coletivos quebrando o silêncio: mulheres feministas e evangélicas na luta contra a violência de gênero e em favor à legalização do aborto
}

\author{
Collectives breaking the silence: evangelical feminists in the \\ fight against gender violence and in favor of \\ legalization of abortion
}

Colectivos rompiendo el silencio: feministas evangélicas
en la lucha contra la violencia de género y por la
legalización del aborto

Recebido em 31-08-2020

Modificado em 03-10-2020

Aprovado para publicação em 14-11-2020

\section{Milena Geisa dos Santos Martins}

ORCID: 0000-0002-5664-8880

Mestra em Ciências Sociais pela Universidade Federal Rural do Rio de Janeiro (UFRRJ), Brasil. Integra, como pesquisadora e analista de mídias sociais, o grupo de pesquisa: Dinâmicas Territoriais, Cultura e Religião (CRELIG). E-mail: milenamartins18@gmail.com

\section{Resumo}

Nosso objetivo neste artigo, a partir de entrevistas e netnografia, é mostrar-lhes que a partir do âmbito religioso emergem coletivos cujas as vozes dissonantes não compactuam com a subjugação feminina implementada pela religião e denunciam em ambientes virtuais a violência praticada contra a mulher em ambientes domésticos ou eclesiais. Além de trabalharem voluntariamente instruindo e acolhendo vítimas de violência, é importante destacar que as Feministas Evangélicas, por nós pesquisadas, lutam em favor da legalização do aborto, pois entendem que esta é uma questão de saúde pública. Porém, mesmo lutando em favor dos direitos femininos, elas são ameaçadas por indivíduos que possuem ethos familista e visão conservadora de mundo, pois estes entendem que elas querem destruir a família.

Palavras-chave: Feminismo; religião; violência de gênero; política. 


\section{Introdução}

Becker (2008) afirma que, ao fazermos uma pesquisa, não devemos ir a campo esperando saber todas as respostas. Em concordância com Becker reiteramos que, desde o princípio, estamos na contramão do que pensa o senso comum a respeito das mulheres evangélicas. Embora pareçam ser mulheres submissas, acríticas e extremamente dedicadas à família, em nossa concepção faz-se necessário praticar o que Da Matta (1978) chama de Anthropological Blues e, desse modo, estranhar o que é familiar e familiarizar-se com o que é diferente. Nesse sentido, acreditamos que fizemos ricas descobertas ao voltarmos nosso olhar para as mulheres que se consideram evangélicas e também feministas.

No que diz respeito a este artigo, aproveitamos para destacar que, embora a religião evangélica possua ampla segmentação, não é nosso objetivo detalhar as particularidades de cada vertente denominacional. Há outros autores que cumpriram suas propostas de identificar e discernir as peculiaridades de cada grupo desde sua fundação, tais como: 1) o livro "Evangélicos" (Mafra, 2001); 2) e os artigos "O protestantismo no Brasil e suas encruzilhadas" (Mendonça, 2005) e "Protestantismo no Brasil: Um caso de religião e cultura" (Mendonça, 2007). Portanto, em lugar de nos aprofundarmos nas características de cada denominação, optamos por identificar e estudar as questões que perpassavam por "todas" elas. A caráter de ilustração, como já era esperado, constatamos que a violência de gênero é experienciada por todas as mulheres evangélicas, independente da vertente religiosa que pratiquem.

Nosso objetivo neste artigo é mostrar-lhes que emerge do âmbito religioso, tido como tradicional, vozes dissonantes que não compactuam com a subjugação feminina e denunciam toda e qualquer violência praticada contra a mulher, tanto dentro quanto fora de ambientes domésticos e eclesiais. Entretanto, por razões de tradição e de predominância masculina em lugares de poder, tais vozes são impedidas de se professarem dentro das igrejas.

Como meio de externalizar os gritos que até outrora eram mudos, mulheres que se consideram feministas e evangélicas, como as Feministas Evangélicas ${ }^{1}$ que estamos a analisar, passam a utilizar a Internet como veículo e aporte para suas lutas contra o patriarcado, sobretudo o religioso. Porém, a atuação das Feministas Evangélicas na rede, embora seja de grande proveito para indivíduos e grupos sociais que compartilham dos

1 Destacamos aqui que as Feministas Evangélicas são mulheres que se autodenominam evangélicas e também feministas 
mesmos valores e modos de pensar, não é capaz de promover mudança nas mentalidades de sujeitos com visões tradicionais de mundo.

Nosso primeiro contato com as Feministas Evangélicas deu-se por meio do grupo virtual, na rede Facebook, chamado "Feministas Cristãs"'. No grupo, só é permitido o acesso de mulheres após análise e aprovação das mediadoras. Sendo assim, por sermos do sexo feminino, afirmamos que nossa inserção no grupo ocorreu sem maiores esforços.

Mas quem são as feministas evangélicas? De acordo com nossa pesquisa, são mulheres com idades entre 20 e 45 anos, moradoras de áreas urbanas periféricas, graduadas e Pós-Graduadas em instituições de ensino superior. Além disso, afirmamos que a aquisição da educação formal foi o principal fator para a desconstrução da concepção dos tradicionais papéis de gênero e do sentimento de culpa implantada pela religião. Por isso, as classificamos como uma elite intelectual que se coloca na esfera religiosa como defensora dos direitos femininos e tradutora das teorias feministas para a linguagem feminina popular. Elas objetivam instruir as mulheres a identificarem e combaterem a violência de gênero dentro dos espaços religiosos e domésticos. Faz-se necessário, também, explicitar que todo o trabalho desenvolvido pelas militantes é realizado de modo voluntário. Elas declaram, em entrevista, não recebem fomento de nenhuma ordem.

É importante destacar que, embora não tenhamos feito nenhum levantamento quantitativo no que diz respeito à raça, muitas mulheres negras também fazem parte dos coletivos feministas evangélicos na internet. Por isso, devido a resultados confirmados em outras pesquisas $^{2}$ no que diz respeito à predominância de mulheres negras em religiões de matriz pentecostal ou neopentecostal, supomos que pessoas afrodescendentes do gênero feminino sejam maioria dentro do movimento feminista evangélico.

No tocante à metodologia, antes de tudo, faz-se necessário informar às leitoras e leitores que fundamentamos a pesquisa sobre resultados adquiridos a partir de netnografia e de entrevistas virtuais: 1) A opção pelo método de netnografia se justifica pelo fato de nosso objeto ser muito atuante no Facebook ${ }^{3}$. Além disso, essa é a rede social mais utilizada quando

\footnotetext{
${ }^{2}$ Nome dado a um grupo privado na rede social Facebook no qual participam, além de evangélicas, mulheres católicas e Kardecistas. A escolha do nome, Feministas Cristãs, se deu pelo fato das idealizadoras do grupo terem a intenção de agregar demais religiões cristãs que não somente a evangélicas em virtude de reconhecerem muitas similitudes em relação às correntes religiosas. Para além das aproximações e similitudes religiosas, o próprio gênero também é fator de aproximação entre as integrantes. Segundo Thayô, uma das idealizadoras, por conta do gênero o que uma mulher católica sofre não difere tanto das experiências vivenciadas por kardecistas ou evangélicas.

2 Cf. Jacob et. al (2003).

3 Destacamos que no tocante a atuação de evangélicos progressistas na mesma rede social, há outras páginas como: Vozes de Maria (ligada às questões feministas), Evangélicos pelo Estado de Direito (referente ao debate de questões políticas) e Evangélicxs (relacionado à defesa de questões da população LGBT).
} 
um grupo almeja gerar mobilização social (Rossini, 2014); 2) Escolhemos realizar entrevistas em profundidade, porque entendemos o discurso proferido pelas informantes como sendo uma versão real, e, portanto, representativa, de suas vivências. Desse modo, a partir das narrativas das entrevistas, foi possível identificar repetições que nos levaram a um ponto de "saturação 4 " e nos permitiu retornar à teoria para começar a produzir o material final da pesquisa, tal qual recomenda Duarte (2002).

Ao todo foram entrevistadas 8 mulheres, dentre elas negras e brancas, dentro de uma faixa etária que variou entre 20 e 45 anos de idade. Todas as entrevistas tiveram duração entre 90 e 120 minutos. A maioria delas ocorreu durante o período da noite e algumas só foram possíveis durante as noites de sábado, estes foram os momentos nos quais elas conseguiram nos encaixar em suas agendas de dupla/trilha jornada diária. Entretanto, mesmo as entrevistas sendo realizadas em dias e/ou horários não usuais, todas as entrevistas aparentam vitalidade e motivação para transmitir informações.

Percebemos que as feministas evangélicas atuam de modo descentralizado no ambiente virtual. Portanto, voltamos nosso olhar para os seguintes sítios virtuais: 1) grupo: Feministas Cristãs; 2) página: Evangélicas pela Igualdade de Gênero; 3) página: Projeto Redomas; 4) página: Frente evangélica pela Legalização do Aborto. Além disso, também analisamos informações produzidas sobre elas pela mídia tradicional ${ }^{5}$. Portanto, a netnografia realizada durante 18 meses, nos instrumentalizou na busca por pontos de congruência em meio a diferentes interconexões de pensamentos, vivências, práticas e discursos desenvolvidos e manifestados em mais de um ambiente ${ }^{6}$.

Entretanto, ressaltamos que, embora estivesse em nosso planejamento entrevistar também a idealizadora da página Frente Evangélica pela Legalização do Aborto, não obtivemos seu retorno após algumas tentativas de contato. Supomos que não conseguimos entrevistá-la porque a mesma estava se organizando para sair do país após receber ameaças de morte. A explanação sobre seu autoexílio nos foi dada por uma de nossas entrevistadas e, posteriormente, confirmada pela imprensa ${ }^{7}$.

\footnotetext{
4 Um dos pontos de saturação, por exemplo, foram os recorrentes relatos sobre o sentimento de culpa que as mulheres evangélicas disseram sentir quando se descobriram feministas. Pensavam que por terem se tornado feministas estavam traindo Deus.

5 A fundadora da página Frente evangélica pela Legalização do aborto teve uma participação no programa Amor e Sexo da rede Globo no ano de 2018. Disponível em https://globoplay.globo.com/v/7159808/

6 Temos consciência de que, ao voltar nosso olhar para múltiplos campos de análises, corremos o risco de não coletar dados importantes. Porém não objetivamos fazer análises completas de todo conteúdo disponibilizado por elas em cada sítio virtual, mas sim realizar a integração de dados/fatos recorrentes.

7 Veremos posteriormente na sessão Conservadorismo Religioso: Evangélicos extremistas contra progressistas.
} 
No que tange à estrutura deste artigo, além desta introdução, há três tópicos. No primeiro, debateremos a respeito da importância da internet como ferramenta de informação, de militância e de acolhimento para as feministas evangélicas. No segundo, trataremos sobre as violências de gênero e as práticas de aborto em meio a mulheres religiosas. E no terceiro, mostraremos o embate ideológico entre evangélicos conservadores/tradicionais e progressistas pela disputa de poder no campo político.

Também queremos ressaltar que, mediante às falas de nossas entrevistadas e a ataques promovidos por indivíduos de orientação tradicional contra ativistas no ambiente virtual, identificamos que a luta das Feministas Evangélicas não vislumbra apenas garantir direitos somente às mulheres evangélicas, mas defender as minorias como um todo. Visto que, segundo elas, religião e política não devem se misturar. Veremos no terceiro tópico o porquê de elas defenderem a laicidade do estado. Comunicamos, ainda, que utilizaremos a presença das Feministas Evangélicas na Internet apenas como pano de fundo para orientar o leitor a respeito do surgimento e da atuação delas no cenário social. Justificamos que não daremos ênfase à sua militância na esfera virtual, pois abordamos esse assunto de modo exclusivo em outra oportunidade (Martins; Guedes, 2019).

\section{Evangélicas progressistas e a mobilização da internet como instrumento de luta (fé)minista}

Desde cedo, o movimento feminista percebeu a importância dos meios de comunicação no que diz respeito à conquista de visibilidade para suas causas. Entretanto, o movimento constatou também que os meios de comunicação sofrem marcada influência da dominação masculina. Portanto, a partir da segunda onda ${ }^{8}$ feminista, iniciou-se a utilização de mídias alternativas pelas próprias mulheres, para defenderem suas pautas, suas lutas e combaterem os discursos dominantes. Segundo Woitowicz (2012), dentro deste contexto de necessidade de uma mídia que permitisse voz às mulheres de luta, surgiram os jornais "Brasil Mulher" (1975-1979), "Nós Mulheres" (1976-1978) e "Mulherio" (1981-1987), que estavam estritamente relacionados ao processo de oposição à ditadura militar.

8 A primeira onda feminista, compreendida entre a segunda metade do séc. XIX e o fim da Segunda Guerra Mundial, foi um período no qual as ativistas revindicavam: melhores condições de trabalho, educação e o direito ao voto feminino. Durante a segunda onda, surgiram outras demandas. As lutas feministas giraram em torno do direito à liberdade sexual e da maior atuação da mulher no cenário público. 
Após os anos de 1990, o feminismo encontrava-se circunscrito a ONGs e grupos de pesquisa. Já os jornais feministas, enfatizaram suas produções em temas de questões políticas, de saúde e demandas sociais. Aqui é possível citar alguns deles:

\footnotetext{
Os jornais Fêmea, do Centro Feminista de Estudos e Assessoria; Fazendo o Gênero, do grupo Transas do Corpo; Jornal da rede, da Rede feminista de saúde, direitos sexuais e direitos reprodutivos; e "Folha Feminista", da Sempreviva organização feminista (Woitowicz, 2012:06).
}

A partir desse período, o feminismo passou a utilizar como principal recurso estratégico para defesa e difusão de suas causas os meios alternativos de comunicação. Contudo, as formas de atuação e dinâmicas de articulação do movimento de mulheres no mundo todo mudaram bastante com o advento da internet nos anos 1990. Este processo, vivenciado por outros movimentos sociais, ganha expressão particular no movimento feminista em função desta nova ferramenta tecnológica se consolidar historicamente como um canal mais livre e eficiente, lugar de práticas e expressões coletivas.

Durante a década de 90, diversos grupos feministas entraram na disputa pela garantia de expressão e espaço de seus discursos na internet. Um dos objetivos do movimento era instaurar e legitimar políticas de inclusão das mulheres no meio digital. Como nos meios de comunicação massiva e hegemônica, as informações passam por uma seleção, sendo adaptadas ou simplesmente ignoradas e excluídas antes de serem publicadas, a internet se mostrava mais interessante, uma vez que a transmissão das notícias/narrativas ocorre de maneira dinâmica e direta. Ou seja, as mídias digitais permitem que os indivíduos, a partir da autocomunicação, sejam protagonistas da própria vida ao serem capazes de disseminar na rede o conteúdo produzido por eles. Em outras palavras, a internet, quando comparada com as mídias de massa, é uma revolução, pois, com seu advento, os indivíduos deixaram de ser apenas receptores (Castells, 2013; Miskolci, 2016).

Isso também é o que aponta Gohn (2011). Para a autora, a Internet é um lugar no qual movimentos sociais se comunicam, se organizam e fazem suas reivindicações. Em concordância com Gohn, entendemos que a internet, para além de um recurso, é palco e meio condutor de lutas sociais, visto que diferentes grupos se apropriam e se beneficiam dela em suas lutas, tais como as mulheres que unem gênero, religião e militância - este é o caso aqui analisado. 
Foi exatamente no ambiente virtual que tivemos conhecimento a respeito da existência de Feministas Evangélicas. Encontramo-las no grupo Feministas Cristãs ${ }^{9}$, dentro dos domínios da rede social Facebook. Tal espaço foi criado porque, como relatou Thayô Amaral $^{10}$ à $B B C N E W S^{11}$, o objetivo era ter um lugar no qual mulheres que se consideram feministas e evangélicas pudessem se reunir para debater questões sobre religião e feminismo sem serem expostas a insultos e confrontos, pois, segundo ela, as feministas seculares ${ }^{12}$ tendem a não entender como pode ser possível a união entre as esferas militante e religiosa.

Ainda segundo Thayô, nos grupos virtuais compostos por feministas seculares, sempre havia preconceito e desconfiança em relação a ela por conta de sua crença religiosa. Nossas entrevistadas também nos relataram ter passado pelo mesmo problema que Thayô. Nas palavras de Valeria Vilhena ${ }^{13}$ : "Eu não concordo com a imposição advinda de feministas seculares que cobram um posicionamento feminista não religioso. Para isso temos a teologia feminista ${ }^{14}$ como um instrumento de luta essencial para o trabalho de desconstrução do preconceito das feministas seculares." Noemi ${ }^{15}$ também se manifesta:

Vez ou outra sou confrontada por feministas não evangélicas que acreditam não ser possível a junção das duas ideologias. Assim como o feminismo negro, o feminismo trans, o feminismo LGBT, o feminismo evangélico nada mais é que o um recorte do olhar feminista a partir da experiência comum de muitas através da lente da fé cristã. Desse modo, independente da vertente feminista que melhor lhe representa, a mulher cristã evangélica aliará suas ideologias ao seu eu (Noemi, entrevista cedida em 24 de Abril de 2019).

Para as Feministas Evangélicas, é importante compartilhar suas experiências vivenciadas no meio religioso, porque entendem que o feminismo não é, e não pode ser, um movimento único, no qual somente as experiências de um determinado grupo feminino é considerado. Acreditam que o feminismo deve ser constituído e articulado mediante às variadas experiências femininas. Para isso, entendem ser necessário que as Feministas Seculares as escutem com o objetivo de instrumentalizar a luta. E justificam que, assim como

9 Quanto ao nome do grupo, Thayô nos informou que preferiu chamá-lo de Feministas Cristãs - ao invés de Feministas Evangélicas - para que mulheres provenientes de outros segmentos religiosos se sentissem acolhidas. É importante ressaltar que o grupo é composto por mulheres cristas católicas, kardecistas e também por mulheres pertencentes a religiões de matriz afro.

10 Uma das criadoras do grupo virtual Feministas Cristãs.

11 Disponível https://www.bbc.com/portuguese/noticias/2015/07/150729_salasocial_evangelicas_feministas_cc 12 Decidimos classificar deste modo as mulheres que são feministas sem religião.

13 Criadora do coletivo Evangélicas pela Igualdade de Gênero, como veremos a seguir.

14 Segundo Rosado-Nunes (2001), a maior produção feminista teológica no Brasil vem das vertentes protestante e católica, possuem institucionalização e respeito da academia.

15 Destacamos que somente os seguintes nomes mencionados são verdadeiros: Thayô Amaral, Valeria Vilhena e Camila Mantovani (que aparecerá ainda nesta sessão). Portanto, qualquer outro nome mencionado neste artigo é um pseudônimo que visa resguardar a identidade das entrevistadas que não são figuras públicas. 
mulheres brancas não possuem exatamente as mesmas experiências que mulheres negras na sociedade, mulheres sem religião também não passam por situações de opressão como as religiosas, uma vez que as mulheres não religiosas estão livres da culpa ocasionada pela manipulação ideológica que as religiosas podem sofrer por conta da introjeção de dogmas religiosos pelos pastores e da constante vigilância moral praticada pelos membros da comunidade eclesial sobre as ações individuais.

Destacamos, inclusive que mulheres de qualquer religião podem ser vítimas de violência gênero e/ou simbólica porque os possíveis abusos são favorecidos por vulnerabilidade ${ }^{16}$ emocional atrelada à crença religiosa. Portanto, entendemos a presença das Feministas Evangélicas no debate feminista como central e estratégica pois sua vivência no universo religioso permite a construção de um diálogo mais eficaz com mulheres que possuem outras crenças/vivências religiosas. Elas defendem que deve-se identificar e combater os abusos espirituais sem que as mulheres tenham que abandonar as práticas religiosas que fazem sentido a seus universos pessoais.

Avaliando as discussões das mulheres nos espaços virtuais referentes aos coletivos por nós estudados e as falas de nossas oito entrevistadas, consideramos que seus modos de pensar e suas atuações na sociedade são legítimas, visto que, por conta de suas vivências, há uma imensa heterogeneidade de sujeitos femininos (Roese, 2015). Ademais, é importante para pensarmos, a partir da perspectiva de Woodheard (2002), que as mulheres religiosas não devem ser vistas como "marionetes" do patriarcado, mas como agentes racionais que objetivam reformar a religião tradicional por meio da reivindicação de direitos e oportunidades mais igualitárias. Concordamos com as autoras, pois percebemos em nosso campo que questionamentos advindos desses sujeitos estão, de fato, ocorrendo e tensionando o campo religioso, como veremos mais adiante. É importante ressaltar que, ao o que tudo indica, o vetor propulsor de reivindicações femininas no campo religioso dar-se por conta de

16 “(...), é preciso assinalar não só que as tendências à "submissão", dadas por vezes como pretexto para "culpar a vítima”, são resultantes das estruturas objetivas, como também que essas estruturas só devem sua eficácia aos mecanismos que elas desencadeiam e que contribuem para sua reprodução. O poder simbólico não pode se exercer sem a colaboração dos que lhe são subordinados e que só se subordinam a ele porque o constroem como poder. (...), temos que registrar e levar em conta a construção social das estruturas cognitivas que organizam os atos de construção do mundo e de seus poderes. Assim se percebe que essa construção prática, longe de ser um ato intelectual consciente, livre, deliberado de um "sujeito" isolado, é, ela própria resultante de um poder, inscrito duradouramente no corpo dos dominados sob forma de esquemas de percepção e de disposições (a admirar, respeitar, amar etc.) que o tornam sensível a certas manifestações simbólicas de poder" (Bourdieu, 2012:52-53 [grifos nossos]). Isto é, as mulheres religiosas tendem a suportar os domínios e as agressões por parte de suas lideranças espirituais, pois creem que esses indivíduos são manifestações diretas de algo tido por elas como divino/sagrado. 
seus avanços na esfera da educação ${ }^{17}$. Ou seja, a partir dos conhecimentos adquiridos no ensino superior ${ }^{18}$, novas visões ${ }^{19} \mathrm{e}$ interpretações de mundo foram construídas. Entretanto, não atribuímos o crescimento do feminismo evangélico somente à escolarização feminina, mas também à circulação de seus ideais feministas no meio virtual, dada a característica difusora que ele possui.

Retomando a discussão a respeito do grupo Feministas Cristãs, identificamos que o mesmo se constituiu, tal qual planejado por Thayô Amaral e demais idealizadoras, como um $\operatorname{lugar}^{20}$ no qual é possível a (re)união de mulheres feministas e religiosas para debates de assuntos pertinentes às suas vivências. No início, o grupo estudado por nós tinha apenas 400 membras. Atualmente, são mais de $5 \mathrm{mil}^{21}$. Constatamos que este considerável crescimento deu-se mediante ao compartilhamento de experiências pessoais semelhantes que geraram, na coletividade, identificação e, consequentemente, sentimento de pertencimento (Gohn, 2011), o que contribui para que as mulheres se unissem de maneira espontânea. Dito de outro modo, indicamos que as feministas evangélicas, ao criarem ambiente virtual específico para o suprimento de suas próprias necessidades, possibilitaram o agrupamento de mulheres que possuíam desejos idênticos, mas estavam dispersas na rede e na sociedade em geral. Assim, "aqueles que eram excluídos passam a se sentir incluídos em algum tipo de ação de um grupo ativo" (Gohn, 2011:336).

Posteriormente, dentro do grupo Feministas Cristãs, tivemos conhecimento de outros lugares, dentro da mesma rede social, nos quais pudemos encontrar mais pessoas que se autodenominavam feministas e evangélicas e produziam conteúdos e discussões a cerca do

17 Feministas Evangélicas são mulheres jovens, na faixa etária de 20 a 45 anos e em sua maioria, pertencentes a camadas populares da sociedade. É importante destacar que, segundo elas, nenhum outro familiar teve acesso ao ensino superior, sendo elas a primeira geração a alcançar esse feito. Além disso, umas das moderadoras da página Evangélicas pela Igualdade de Gênero, na rede social Facebook, afirmou que 70\% das seguidoras são graduadas em Teologia ou em Ciências Sociais.

18 Mendonça (2005) faz um mergulho no passado e nos mostra que a aquisição do ensino superior por indivíduos religiosos foi um vetor que extrema importância para a transformação de seus valores e visão de mundo. Segundo o autor: "O protestantismo, já em sua terceira geração no Brasil, formara em seu seio uma juventude burguesa intelectualizada pelo acesso às universidades que foram surgindo no período anterior. Treinados para liderança em suas igrejas, esses jovens começaram a ter logo prerrogativa nos quadros estudantis que formavam os centros acadêmicos nas escolas superiores e, assim, passaram a ver a realidade sob outro ângulo, ou melhor, voltariam suas faces para o mundo real. Perceberam o quanto suas igrejas estavam alheias ao que se passava fora de suas portas. Passaram a falar outra língua e se abriu um vazio entre eles e as lideranças eclesiásticas" (Mendonça, 2005:59-60).

19 A aquisição de educação formal traz novas visões de mundo para as mulheres e amplia o universo de escolhas femininas (Machado, 2005; Guedes, 2008).

20 Segundo Rossini (2014), grupos virtuais são organizados por indivíduos que possuem interesse e/ou causas em comum.

21 Disponível em: https://www.facebook.com/groups/678778715492169/members 
tema. Eles são: Evangélicas pela Igualdade de Gênero, Projeto Redomas e Frente Evangélica pela Legalização do Aborto.

Ressaltamos, ainda, que identificamos que mulheres integrantes do grupo Feministas Cristãs também são seguidoras dos outros espaços virtuais mencionados. Ou seja, o fazer feminista evangélico não é excludente, mas associativo. De modo que as mulheres, tanto as seguidoras $^{22}$ quanto as militantes, podem acompanhar e/ou integrar mais um de coletivo. Acreditamos que isso ocorre porque os conteúdos emitidos e compartilhados, tanto no grupo quanto as páginas pesquisadas, defendem as mesmas pautas no que diz respeito à defesa e à valorização feminina dentro dos espaços religiosos e da sociedade como um todo.

Observando e mapeando a referida militância feminista evangélica na rede, percebemos que a Internet lhes proporciona as seguintes possibilidades: luta por reconhecimento, denúncia de abusos e violências sofridas por mulheres em ambiente religioso e/ou doméstico, acolhimento e orientação de vítimas, realização de trabalho pedagógico/informativo a respeito de $\operatorname{assuntos}^{23}$ relacionados ao universo feminino e construção de relacionamentos com seus pares de luta.

É importante destacar que, para além de não serem ouvidas pelas feministas seculares, as feministas evangélicas também são ignoradas por suas irmãs e irmãos de fé (Martins; Guedes, 2019). A exclusão de pessoas que possuem pensamento divergente da maioria é apontada por Vital da Cunha et. al (2017). Segundo eles, os evangélicos progressistas, isto é, aqueles que fazem uma leitura historicizada da Bíblia e defendem os direitos humanos e das minorias, não têm voz em suas igrejas e tendem a se articular em coletivos visando promover na esfera pública a transformação social em que acreditam por meio de seminários, eventos, campanhas de conscientização e rodas de conversa.

Ao analisarmos as Feministas Evangélicas diante de uma perspectiva religiosa, as classificamos como evangélicas progressistas - por se mobilizarem em prol de mudanças e de defesa das minorias. Estudando-as a partir de um recorte secular, consideramos essas mulheres como potenciais ${ }^{24}$ agentes coletivos dos novos movimentos sociais. Defendemos

22 Pessoas que consomem o conteúdo produzido pelas criadoras e/ou administradoras das páginas e podem interagir somente através de comentários ou reações (que são entendidas como as 5 opções de manifestação emocional em relação ao conteúdo emitido nas páginas). Entretanto, é importante ressaltar que no Grupo Feministas Cristãs, toda integrante do grupo pode ser uma produtora de conteúdo.

23 Violência de gênero, legalização do aborto, questões raciais, divisão sexual do trabalho, parto humanizado, violência obstétrica, sexualidade, métodos contraceptivos, política... entre outros. Todos os assuntos sobre os quais mencionamos são postados e comentados no grupo e nas páginas da rede social. Informamos que essas afirmações foram embasadas em informações colhidas por meio da técnica de netnografia.

24 Pensando em consonância com Gohn (2017), dado ao pouco tempo de aparição das feministas evangélicas no Brasil, não podemos afirmar que elas compõem categoria dos novos movimentos sociais. Isto é, ainda não é possível prever se os coletivos permanecerão organizados e articulados em prol de suas lutas. 
esta linha de pensamento porque, com base na literatura ${ }^{25}$, percebemos em nosso campo que: 1) elas se manifestam de modo pacífico; 2) se organizam de maneira horizontalizada e lutam por conquistas de ordem simbólica: por exemplo, batalham em prol do direito à proteção de mulheres em situação de violência e do desejo de serem consideradas dentro do feminismo e da religião. Ou seja, não são reivindicações de ordem imaterial ${ }^{26}$.

Além disso, é indispensável notar que os coletivos feministas evangélicos por nós pesquisados emergiram após as mulheres refletirem sobre suas próprias experiências com a religião. Portanto, em concordância com Gohn (2011), pensamos esses coletivos como possíveis movimentos sociais. Pois as integrantes "possuem identidade, têm opositor e articulam ou fundamentam um projeto de vida e de sociedade (...) têm contribuído para organizar e conscientizar a sociedade" (Gohn, 2011:336). Ou seja, A): sua identidade se afirma e se mantém pela união entre o feminismo e a fé; B) seus opositores são, principalmente, as lideranças religiosas porque pregam um evangelho que enaltece a figura masculina, desvaloriza a feminina e contribui para a legitimação da prática da violência contra a mulher; C) o trabalho que exercem de maneira voluntária tem como objetivo instruir e conscientizar as mulheres sobre problemáticas que as vulnerabilizam e/ou aniquilam suas vidas. Estamos nos referindo, especialmente, à violência de gênero e à prática do aborto inseguro. É sobre esses assuntos que debruçam os coletivos Evangélicas pela Igualdade de Gênero, Projeto Redomas e Frente Evangélica pela Legalização do Aborto e será sobre essas temáticas que discutiremos na próxima seção.

\section{Realidade feminina: violência de gênero e a prática de aborto inseguro}

Identificamos, em nosso campo, que a violência de gênero é uma questão que perpassam a vida de muitas mulheres religiosas de maneira recorrente. Além disso, acontecimentos violentos também podem levá-las à morte. Preocupadas com isso, as Feministas Evangélicas dos coletivos Evangélicas pela Igualdade de Gênero ${ }^{27}$ e Projeto

25 Gohn (2017); Perez, et al. (2017).

26 É importante destacar que autores, como Gohn (2017); Perez, et al. (2017), apontam que a demanda por conquistas simbólicas é uma característica dos novos movimentos sociais.

27 O grupo Evangélicas pela Igualdade de Gênero foi criado, por Valeria Vilhena, durante o Fórum Pentecostal Latino-americano e Caribenho (FPLC) no ano de 2015 e surgiu na rede social Facebook através da Página Evangélicas pela Igualdade de Gênero também no mesmo ano. Atualmente, a página conta com 5.211 seguidores. [Consult. 15-11-2019]. Disponível em: https://www.facebook.com/mulhereseig/ . Além disso, com o passar dos anos, o coletivo cresceu e outros "pontos de atuação" surgiram: EIG Belo Horizonte, EIG Londrina, EIG Espirito Santos, EIG Goiânia e EIG Rio de Janeiro. Entretanto, não são espaços físicos. As mulheres se organizam em ambiente virtual e cumprem a agenda do coletivo em feiras, congressos e igrejas. Também 
Redomas $^{28}$ têm o objetivo de discutir assuntos referentes à violência e ao assédio contra mulher no meio público, privado ou religioso para instrumentalizá-las a identificar e denunciar toda e qualquer situação de abuso e/ou agressão.

Segundo Valéria Vilhena (2009), criadora da $\mathrm{EIG}^{29}, 40 \%$ das mulheres evangélicas, que fizeram tratamento psicológico na Casa Sophia, durante o período no qual a autora realizou sua pesquisa de mestrado, viviam em situação de violência doméstica. Mediante informações advindas das entrevistas e de relatos publicados nos espaços virtuais feministas evangélicos, muitas mulheres em situação de violência são orientadas por suas lideranças a resolverem o problema por meio da oração. A este respeito, Noemi relata:

Eles dizem sempre para você orar e manter um bom relacionamento com o marido. O discurso nunca é do tipo: 'olha se ele tiver te agredindo, é melhor você rever aí porque não dá pra continuar com um marido assim'. Então, mesmo as pastoras, reproduzem o discurso machista sim (Noemi, entrevista cedida em 24 de Abril de 2019).

Também na teoria encontramos o que o campo já nos apontava. Segundo Mafra (2001), na década de 1990, a sociedade civil do Rio de Janeiro criou a Campanha pela Redução da Violência contra a Mulher. Sabendo que as igrejas possuem acesso às mulheres periféricas que não são amplamente abarcadas pelo Estado, convidaram os evangélicos para atuar unidos à sociedade civil nesses espaços de maior segregação social e de ausência de manifestação do poder público. Entretanto, o engajamento foi ínfimo devido à discordância entre agentes religiosos e ativistas. Os evangélicos, por não concordam com a prática de medidas protetivas para a superação da violência, defendem que a unidade familiar deve ser preservada (Mafra, 2001). Além disso, é comum a crença de que o problema deve ser resolvido através da oração e da prática de um comportamento submisso e passivo por parte da mulher para que a ira do marido não seja despertada (Vilhena, 2009). Também por conta da crença na eficácia do poder da oração, dentro de muitas comunidades evangélicas, a mulher que denuncia o companheiro é estigmatizada. Ela é considerada fraca e descrente da capacidade de provisão/proteção divina por recorrer a medidas jurídicas. Entendemos, portanto, que no meio evangélico tradicional, a "justiça dos homens" é considerada inferior à justiça de Deus. Contra isso, e objetivando tanto conscientizar as mulheres de que denunciar o agressor é um direito delas quando desconstruir o pensamento de culpabilização feminina pela

responsáveis por tentar angariar fundos para o desenvolvimento do trabalho junto aos órgãos públicos municipais e Estaduais. A EIG Londrina, por exemplo, conseguiu o apoio da prefeitura.

28 A página do Projeto Redomas na rede social Facebook atualmente possui 5.526 seguidores. Disponível em https://www.facebook.com/projetoredomas

29 Evangélicas pela Igualdade de Gênero. 
ocorrência da violência, o Projeto Redomas criou um material ${ }^{30}$ pedagógico intitulado: "Não é falta de oração - cartilha de combate à violência contra mulher em igrejas e comunidades cristãs" (Projeto Redomas, 2018). Amparadas pela Lei Maria da Penha ${ }^{31}$, por meio do material, elas instruem que a violência contra a mulher é designada como toda e qualquer atitude $^{32}$, bem como intenção, que "cause morte, sofrimento físico, psicológico ou sexual às mulheres" (Projeto Redomas, 2018:3). Entretanto, mesmo com a exposição de inúmeros relatos de ocorrência de violência de gênero nas redes, muitas autoridades eclesiais continuam negando a existência do problema e optam por não debatê-lo com os fiéis.

Em entrevista, Valeria Vilhena nos afirmou que a principal barreira para a atuação das feministas evangélicas nas igrejas é a resistência das lideranças religiosas em dialogar a respeito das agressões. Segundo ela, a maioria do pastorado defende que ninguém sofre violência de gênero $^{33}$ em suas igrejas. Tanto para Valeria quanto para as feministas evangélicas, a postura negacionista, os discursos machistas e a interpretação patriarcal da Bíblia contribuem para a legitimação e perpetuação da violência de gênero. Para elas, é obrigação da igreja acolher as vítimas e promover estruturas nas quais se estimule a desconstrução de antigos padrões. Recentemente, durante o Fórum de Mulheres na Igreja Betesda, a EIG implementou um projeto para mulheres em situação de violência e conseguiu fechar uma parceria entre a igreja e a casa de acolhimento Mulheres Vivas em Santo Amaro/ SP. Os membros da igreja ajudam trabalhando de maneira voluntária e doando recursos para sustento das vítimas e seus filhos. Para além do combate a violência de gênero no ambiente eclesial por meio de sermões, estudos bíblicos e inserção do tema nos currículos teológicos, as Feministas Evangélicas também propõem que as igrejas desenvolvam um órgão responsável para tratar questões que envolvam o combate à violência e que acolha, para além das mulheres vítimas, também os homens agressores, sem deixar de desenvolver, obviamente, práticas e políticas para responsabilizá-lo perante a igreja e a sociedade.

Além de abusos e agressões, outro problema que acomete as mulheres evangélicas é a prática de aborto inseguro. De acordo com dados apresentados pela PNA em 2016 e mencionados por Diniz et al (2017), 10\% das evangélicas, referentes à amostra composta por 37.287.746 mulheres, abortaram pelo menos uma vez na vida. Além disso, ainda com base na

30 Cartilha projeto redomas. Disponível em http://projetoredomas.com/wp-content/uploads/2018/07/cartilharedomas.pdf . Também no site do Projeto Redomas é possível encontrar textos, podcast, estudos bíblicos indutivos, transcrições de áudio de relatos pessoais e materiais a respeito da violência contra a mulher. 31 Lei $11.340 / 2006$.

32 Elas entendem que a agressão não se manifesta de modo exclusivamente físico, mas também de maneira simbólica.

33 Quando utilizamos o termo violência de gênero estamos nos referindo a toda forma de violência sofrida pelo gênero feminino. 
PNA de 2016, Diniz et al (2017) afirmam que mulheres negras abortam mais que as brancas, o que caracteriza um quadro de $15 \%$ contra $9 \%$ - dentro do mesmo espaço amostral supracitado.

Jacob et al. (2003) destacam que os evangélicos, sobretudo os de matriz pentecostal, são maioria nas regiões de periferia dentro das cidades metropolitanas e Machado (2005) afirma que os pentecostais são em sua maioria compostos por mulheres. Logo, se voltamos nossa atenção para os segmentos pentecostais e neopentecostais, veremos que a população é predominantemente composta por mulheres negras e periféricas. Além disso, é importante ressaltar, com base nas pesquisas de Diniz et al 2017, que as mulheres negras são as que mais morrem em decorrência de aborto clandestino.

Diante de amplas recorrências formalizadas em dados estatísticos, as Feministas Evangélicas se manifestam a favor da descriminalização do aborto. Elas defendem que a legalização deve estar acima de qualquer julgamento ${ }^{34}$ religioso ou moral porque é um meio para a preservação da vida das mulheres, visto que a proibição não impede que a prática seja realizada e contribui para que ocorra de modo inseguro, sobretudo em meio à população negra e periférica. Embora nossas entrevistadas tenham nos afirmado que nunca recorreram a um aborto, algumas garantem que recorriam à prática apenas se sofressem um estupro. Além disso, elas defendem que opiniões individuais não podem interferir na coletividade e se mostram contrárias a interferência da religião na política. As entrevistadas alegam, portanto, que toda mulher deve ter o direito de abortar se desejar. Elas justificam que os pesos ${ }^{35}$ provenientes do nascimento de um filho recaem, majoritariamente, sobre os ombros maternos, visto que os pais e o Estado frequentemente são negligentes e/ou ausentes no que tange à divisão da responsabilidade para o sustento da criança.

\footnotetext{
34 Ester, nos traz um novo elemento para o debate; o aborto paterno: "Eu não abortaria, mas em algumas situações eu apoio. Em casos de estupro por exemplo. E eu acho que as mulheres têm que ter esse direito de escolha porque os homens abortam todo dia. Eu fui abortada, né! Eu fui abortada e eu acho que a gente precisa falar do aborto masculino, ninguém fala!"

35 Embora nosso objeto de pesquisa seja as Feministas Evangélicas, não pudemos deixar de notar um fato que o campo nos apontava. Mesmo que Machado (2005) e Teixeira (2014) mostrem que em meio aos pentecostais haja o incentivo da inserção da mulher no mercado de trabalho, ainda há predominância - no imaginário evangélico tradicional - de que a ausência de dedicação exclusiva das mães aos filhos contribui para a ocorrência de envolvimentos dos mesmos com drogas, com situações de violência e demais problemas sociais (Vital da Cunha et al, 2017:128).
} 


\section{Conservadorismo religioso: evangélicos extremistas contra progressistas}

As Feministas Evangélicas defendem que para combater a violência de gênero é necessário quebrar o silêncio. Para isso, uma das formas de comunicação, utilizadas para alertar ou fazer denúncias, são os memes. Traremos, abaixo, dois exemplos que tiveram maior repercussão na página da $\mathrm{EIG}^{36}$.

Figura 1: Memes das Evangélicas pela Igualdade de Gênero sobre assédio

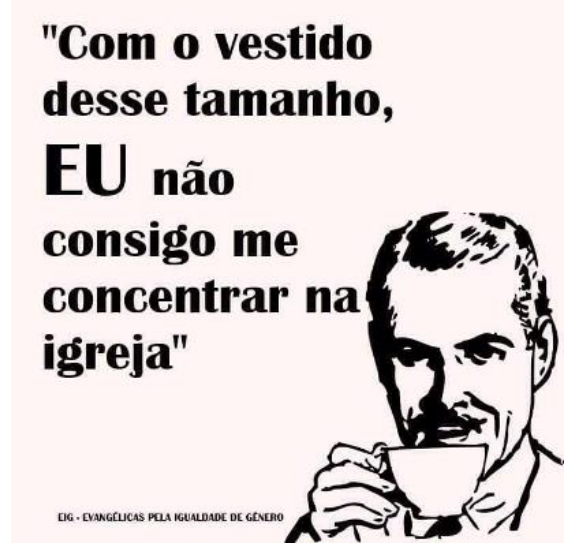

Disponível em:

https://www.facebook.com/mulhereseig/photos/a.59386

$1227419306 / 951222178349874 /$

Figura 2: Memes das Evangélicas pela Igualdade de Gênero sobre violência doméstica

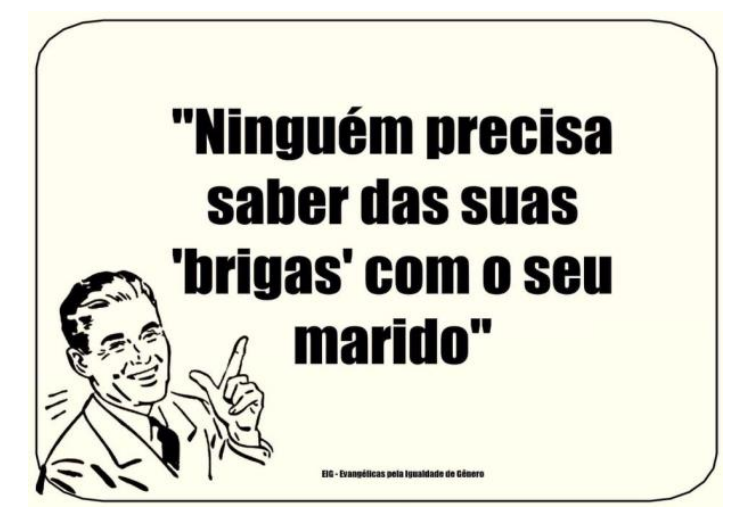

Disponível em:

https://www.facebook.com/mulhereseig/photos/a.59386

1227419306/951643444974414/ 
Para Mian et al (2017), o ciberativismo ${ }^{37}$ são externalizados de diversas formas, a mais nova delas são os memes. Segundo a autora, embora sejam reconhecidos por sua personalidade cômica e estejam associados à "cultura inútil", eles podem refletir a problematização das estruturas sociais e culturais, revelando os hábitos, as crenças e as moralidades dos indivíduos. A partir das ilustrações acima, podemos identificar quais os problemas experienciados pelas mulheres. Além disso, é possível alertá-las e instrumentalizálas a identificar como a violência e o assédio podem ocorrer.

Entretanto, por defenderem as mulheres a partir do trabalho de pedagogização e denúncias nas redes, elas são alvos de ataques no ambiente virtual. Identificamos que isso ocorre porque a religião, embora tenha perdido a centralidade de organização das relações sociais por conta do processo de secularização, ainda exerce influência sobre a agência dos indivíduos em sociedade (Souza, 2004). Logo, é evidente que a postura das mulheres que unem feminismo e religião ofende a moralidade dos indivíduos, religiosos ou não, que possuem uma concepção tradicional dos papéis de gênero de forma cristalizada e inegociável. Por exemplo:

- $\quad$ O grupo Feministas Cristãs, em 2019, desativado pela rede social Facebook. $\mathrm{Na}$ ocasião, suspeitamos que a rede tomou essa medida por conta de recorrentes denúncias recebidas e decidimos entrar em contato com as administradoras para saber o que de fato ocorreu, como e por quê. Fomos atendidos e, em entrevista, Ana nos respondeu que: “O grupo Feministas Cristãs foi arbitrariamente retirado da rede após inúmeras denúncias anônimas afirmando que o grupo praticava e estimular discurso de ódio. Conseguimos acessar a equipe interna do Facebook Brasil em São Paulo, que ouviu nosso caso e reavaliou a denúncia";

- Uma das integrantes do coletivo EIG relatou ter sofrido ameaças de morte advindas de um homem através da internet. Madalena relata: "Em 2016 e início de 2017 eu também tive que ficar um pouco fora das redes porque me ameaçaram de morte e quase chegaram também no meu filho. Eu procurei uma advogada e tomamos as medidas legais";

37 É a forma de ativismo articulado por plataformas virtuais/redes sociais. 
- Camila Mantovani, idealizadora do coletivo Frente Evangélicas pela Legalização do aborto, veio a público declarar que após ter recebido inúmeras ameaças $^{38}$ de morte estava decidindo deixar o Brasil.

No dia 2 de outubro de 2018, Mantovani se apresentou na UFRRJ ${ }^{39}$, na mesa-redonda "Descriminalização do aborto no Brasil: desafios e impasses", e relatou aos ouvintes que as integrantes da Frente Evangélicas Pela Legalização do Aborto recebiam muitas ameaças. Contou, ainda, que a casa de uma delas já havia sido invadida, revirada e pichada na fachada com a seguinte frase: “O salário do pecado é a morte”. Posteriormente, em março de 2019, durante uma entrevista com Noemi, ao nos responder uma pergunta a respeito de ameaças e violência sofridas pelas Feministas Evangélicas, ela nos afirmou que nunca passou por tais situações, conhecia uma pessoa que tinha experienciado. Noemi, então, nos contou que Camila Mantovani estava sendo perseguida e após inúmeras ameaças estava se organizando para deixar o Brasil. A informação concedida por Noemi se confirmou, e veio a público por meio das mídias virtuais e de massa, no dia 26 de abril de 2019. Neste momento, ao considerarmos a notícia jornalística e o relato de Noemi, supomos que Camila, no ano anterior, durante a apresentação na UFRRJ, estava, na verdade, a falar de si mesma. Porém, após recorrentes tentativas, não conseguimos conversar com a militante nem antes e nem depois do exílio.

Entretanto, afirmamos que a repressão violenta não é sentida apenas pelas Feministas Evangélicas. Personalidades do âmbito acadêmico também são alvo de ataques orientados por indivíduos de mentalidade tradicional. Debora Diniz ${ }^{40}$, autora da pesquisa sobre aborto mencionada por nós neste trabalho, deixou o país por ter recebido ameaças de morte. Todavia, para nós, o prelúdio da onda conservadora manifestou-se de maneira violenta ainda em 2017, quando Judith Butler visitou o Brasil e foi verbalmente agredida ${ }^{41}$.

Portanto, percebemos que os ataques não são destinados apenas aos evangélicos progressistas. Eles são orientados a toda e qualquer pessoa, com ou sem ligação religiosa, que são consideradas como transgressoras por religiosos de mentalidade tradicional. As tentativas

38 Disponível em: https:/g1.globo.com/rj/rio-de-janeiro/noticia/2019/04/26/jovem-evangelica-relata-ameacaspor-defender-a-legalizacao-do-aborto-e-vai-deixar-o-brasil.ghtml

39 Universidade Federal Rural do Rio de Janeiro.

40 Disponível em: https://oglobo.globo.com/sociedade/ameacada-de-morte-antropologa-debora-diniz-diz-quehora-de-discutir-aborto-no-brasil-23761500

41 Disponível em:

https://epoca.globo.com/cultura/noticia/2017/11/filosofa-judith-butler-e-agredida-em-congonhas-antes-dedeixar-sao-paulo.html. Disponível em: https://www.youtube.com/watch?v=urNAs80yUDU 
de intimidação e silenciamento ocorrem porque evangélicos extremistas ${ }^{42}$ e/ou conservadores querem impedir o avanço dos evangélicos progressistas e das minorias, como feministas e LGBTs, por exemplo, porque defendem que as transformações sociais exigidas por esses grupos são consideradas pecado a partir de uma interpretação bíblica literal.

Além disso, eles também abominam as Feministas Evangélicas e as acusam de querer destruir a família ${ }^{43}$. Para evangélicos, com concepções tradicionais de mundo, o feminismo vislumbra acabar com a família, pois entendem que a mulher deixa de se dedicar ao lar para se dedicar ao trabalho e realizar desejos pessoais (Vital da Cunha et al, 2017). No meio evangélico, para além das mensagens propagadas pelas lideranças religiosas durante os cultos nas igrejas, lideranças tecem como estratégias de dominação de gênero, disfarçada de ações orientadas à formação e defesa da família, eventos externos com foco no público feminino. O Congresso de Mulheres Diante do Trono, o Culto das Princesas ${ }^{44}$ e o projeto Godllywood ${ }^{45}$ têm por objetivo doutriná-las para submissão ao marido e para o desempenho dos trabalhos não remunerados de reprodução social e care. No Congresso ${ }^{46}$ Mulheres Diante do Trono, ministrado por Ana Paula Valadão ${ }^{47}$, por exemplo, as orientações transmitidas às fiéis abordam o cuidado com a apresentação pessoal e a conduta feminina. É pregado que a mulher deve cuidar do corpo e da aparência, além de se relegarem ao seu lugar de esposa e mãe, pois, segundo a concepção corrente entre diferentes segmentos evangélicos, este foi, segundo creem os evangélicos, o papel destinado a elas por Deus dentro família. Além disso, a cantora e pastora defende que se alguém nasce mulher é porque Deus quis (Rosas, 2016). Logo, dentro da lógica religiosa, desempenhar os tradicionais papéis de gênero ao cuidar da família

42 Evangélicos extremistas, por não concordarem com a leitura que evangélicos progressistas fazem da Bíblia, os acusam de não conhecerem a "Palavra de Deus" e de aliarem aos esquerdopatas de contribuírem para desestruturação da família. É importante ressaltar que a palavra esquerdopatas é utilizada - pejorativamente para classificar pessoas que lutam pelos ideais de esquerda, pelos Direitos Humanos e das minorias. No cenário religioso umas das personalidades que mais fazem uso desta palavra é Silas Malafaia. [Consult. 29-11-2017]. Disponível em: https://www.youtube.com/watch?v=qgffCjMB-7Y

43 Religiosos tradicionais acusam o feminismo de querer acabar com a família e afirmam que ela precisa ser defendida e protegida porque foi a primeira instituição criada por Deus.

Disponível em: https://www.youtube.com/watch?v=3TOvjnixB1Y

Vídeos a respeito do Congresso Mulheres Diante do Trono podem ser encontrados na plataforma Youtube no canal do Diante do Trono.

Disponível em: https://www.youtube.com/user/DTOFICIAL/search?query=congresso+mulheres

44 Filha de Baby do Brasil e Pepeu Gomes. Foi cantora, junto com suas irmãs, no grupo pop musical SNZ criado em 1997 anos. Possui canal no Youtube com 122,855 inscritos.

Disponível em https://www.youtube.com/channel/UCuHnQ1CR-eM5F--sUuDMLUQ

45 Para discussões mais profundas sobre o projeto Godllywood ver: TEIXEIRA, Jacqueline Moraes. Mídia e performances de gênero na Igreja Universal. Religião e Sociedade, Rio de Janeiro, 34(2): 232-256, 2014.

46 Vídeos a respeito do Congresso Mulheres Diante do Trono pode ser encontrado na plataforma Youtube no canal do Diante do Trono.

Disponível em: https://www.youtube.com/user/DTOFICIAL/search?query=congresso+mulheres

47 Valadão possui em seu espaço Oficial no Youtube, com 423,176 inscritos.

Disponível em: https:/www.youtube.com/user/DTOFICIAL 
e do marido é o mesmo que obedecer a Deus. Em suas pregações, Valadão declara, ainda, que é contra as conquistas adquiridas pelas mulheres por meio das lutas feministas, defende que tais conquistas afastam as mulheres de Deus e que a verdadeira felicidade para as mulheres só pode ter atingida através da obediência à vontade divina (Rosas, 2016).

Professando basicamente os mesmos argumentos que Valadão, Edir Macedo ${ }^{48}$ também defende que mulheres foram criadas por Deus para cuidar do marido e da família e não devem ter acesso à educação superior para que não se formarem e servirem a si mesmas. Para Machado e Barros (2009), é a educação superior somada a maior mobilidade de circulação das mulheres a elevadas esferas sociais que proporciona transformação nas percepções dos tradicionais papéis de gênero: "é no segmento das mulheres economicamente ativas e com maior nível de instrução que as representações de gênero tradicionais tendem a ser mais questionadas e onde existe a maior probabilidade de revisões nas identidades femininas" (Machado; Barros, 2009:370).

Identificamos que no meio religioso, a tradição possui a função social de ordenamento da vida dos indivíduos (Giddens, 2002). Portanto, a definição de um mundo conforme os interesses da classe dominante presume a reprodução de suas posições ideológicas para seus dominados por meio da domesticação dos mesmos. Ou seja, é necessário que o habitus seja introjetado sem que os dominados percebam. Nesse sentido, é importante destacar que os que dominam a alta hierarquia eclesial, lutam pelo poder de produção simbólica, e por meio do seu trabalho de pedagogia, regulam, monitoram e moralizam os corpos do gênero feminino, corroborando para um construtivismo moral que promove e reproduz a dissimetria e hierarquia de gênero entre os fiéis (Bourdieu, 1998). Logo, diante do entendimento desses líderes religiosos, a conquista do ensino superior pela mulher promoveria um desequilíbrio no sistema planejado por Deus porque este daria a ela liberdade para "servir a si mesma".

A respeito da transformação que o ensino universitário pode promover, Guedes (2008) também aponta que aquisição de educação formal traz novas visões de mundo para as mulheres e amplia o universo de escolhas femininas. A possibilidade de escolha, indicado pela autora, foi encontrada em nosso campo quando, por meio das entrevistas, identificamos que nossas entrevistadas, após contato com estudos de gênero no ensino superior e com a teologia

48 A fala de Macedo contra mulheres no ensino superior repercutiu na internet. Indicaremos três, dos vários, endereços virtuais.

1) Disponível em: https://www.facebook.com/jovensdeesquerda/videos/463582457832743

2) Disponível em: https://www.youtube.com/watch?v=EZs59KInUnQ

3) Disponível em: https://www.correiobraziliense.com.br/app/noticia/brasil/2019/09/24/interna-

brasil,789307/bispo-edir-macedo-diz-que-mulher-nao-pode-ter-mais-estudo-que-o-marido.shtml 
feminista $^{49}$, deixaram de concordar com posicionamentos estabelecidos e justificados por líderes religiosos como sendo a vontade de Deus. Afirmamos, portanto, que aquisição do ensino superior ${ }^{50}$ foi o principal fator para a desconstrução da concepção dos tradicionais papéis de gênero implantada pela religião. A respeito da educação superior como desconstrutora de fundamentalismos religiosos, trazemos o relato de Ester:

Eu vim de uma família muito pobre e fui a primeira da minha família me formar numa universidade federal, e a maioria nem tem ensino médio. Eu sempre quis estudar porque eu sempre vi a educação como forma de abrir portas. E ao longo dos anos eu fui estudando sobre o feminismo, pesquisando e a Universidade me ajudou muito. Então eu fui me vendo como uma mulher feminista.

Viver pra Cristo é, às vezes, negar a si mesmo. Mas o feminismo, a instrução, a universidade me ajudaram a perceber algumas coisas dentro da religião. Algumas coisas que não são de Cristo. Então, essas coisas fizeram com que eu me afastasse da religiosidade. A Rural é uma Universidade muito boa porque você conhece todo tipo de gente. Eu me vi na Rural, uma assembleiana tradicional, e ali eu aprendi muitas coisas com as pessoas, conheci muitos outros cristãos que são cristãos. Aquela vivência me fez muito bem porque mudou o meu olhar em relação ao cristianismo (Ester, entrevista cedida em 28 de Abril de 2019).

Em outras palavras, a partir de conhecimentos teóricos institucional acadêmico, mulheres adquiriram repertório crítico que as possibilitou deixar de seguir um sistema religioso de regras baseados na submissão e na obediência feminina. Portanto, a partir dos conhecimentos adquiridos no ensino superior $^{51}$ e de outras vivências, novas visões e interpretações de mundo se construíram. Com isso, houve o rompimento da percepção que elas tinham a respeito da religião, e as feministas evangélicas passaram a defender que é extremamente necessário debater o feminismo nas igrejas. Elas alegam que as mulheres precisam ser alertadas sobre existência do domínio masculino e da violência de gênero sobre as mulheres para que saibam como proceder se forem vitimadas. Para Machado (2005):

49 Segundo Rosado-Nunes (2001), os estudos de religião e gênero se estabeleceram no meio acadêmico através do capital simbólico e material das religiões, advindos principalmente do catolicismo, e de agências internacionais de apoio à pesquisa. Embora constate que analisar a religião pela perspectiva do gênero seja uma necessidade para futuros trabalhos, a autora destaca que mesmo antes do século passado as críticas feministas à religião já eram elaboradas por teólogas na Europa e, sobretudo, nos Estados Unidos.

50 Entre as Feministas Evangélicas percebemos que a presença da educação de ensino superior é expressiva. Além de todas as entrevistas nesse estudo serem graduadas e pós-graduadas, umas das moderadoras da página Evangélicas pela Igualdade de Gênero - na rede social Facebook - afirmou que 70\% das seguidoras são graduadas em Teologia ou em Ciências Sociais.

51 Mendonça (2005) faz um mergulho no passado e nos mostra que a aquisição do ensino superior por indivíduos religiosos foi um vetor de extrema importância para a transformação de seus valores e visão de mundo. Segundo o autor: "O protestantismo, já em sua terceira geração no Brasil, formara em seu seio uma juventude burguesa intelectualizada pelo acesso às universidades que foram surgindo no período anterior. Treinados para liderança em suas igrejas, esses jovens começaram a ter logo prerrogativa nos quadros estudantis que formavam os centros acadêmicos nas escolas superiores e, assim, passaram a ver a realidade sob outro ângulo, ou melhor, voltariam suas faces para o mundo real. Perceberam o quanto suas igrejas estavam alheias ao que se passava fora de suas portas. Passaram a falar outra língua e se abriu um vazio entre eles e as lideranças eclesiásticas" (Mendonça, 2005:59-60). 


\begin{abstract}
Parece consensual que a produção de novas formas de subjetividade feminina e a reconstrução das identidades de gênero na sociedade brasileira desta virada de século estão estreitamente relacionadas com o incremento do nível educacional das mulheres, a ampliação da participação em atividades remuneradas, (...) a cultura feminista proporciona os recursos discursivos para o desenvolvimento de uma consciência de gênero e para o combate das relações assimétricas entre os homens e as mulheres (...) a despeito do combate das lideranças religiosas pentecostais ao movimento de mulheres, as mudanças nas representações dos gêneros nesses segmentos confessionais encontram-se também relacionadas com a tendência de apropriação seletiva de ideias feministas pela sociedade, e em especial pelas instituições culturais brasileiras (Machado, 2005:390).
\end{abstract}

Pelo fato das feministas evangélicas pregarem mudanças dentro do sistema eclesial vigente, são vistas por cristãos tradicionais ${ }^{52}$ como desviantes, isto é, sujeitos que promovem a disfunção do sistema e geram a desorganização social quando rompem com a estabilidade do mesmo (Becker, 2008). Através de dados do nosso campo, percebemos que, para os evangélicos tradicionais, as "desviantes" são vistas como impuras, ausentes de comunhão com Deus, e, por isso, devem ser excluídos da comunidade religiosa.

Em contra partida, as Feministas Evangélicas alertam que a interferência dos evangélicos conservadores/tradicionais na política, sob justificativa de proteção à família, é preocupante porque traz práticas e posturas tracionais de cunho exclusivamente religiosos para arena pública. Ou seja, os evangélicos tradicionais se utilizam de suas posições políticas para impor seus preceitos e sua visão religiosa de mundo às vivências pessoais dos demais sujeitos sociais.

O apontamento feito por elas se faz possível, visto que, embora no início do protestantismo, no Brasil, os fiéis costumassem se distanciar de atividades políticas e sociais (Mendonça, 2005:54), a partir da década de 1980, evangélicos começaram a perceber que era necessário estar nos espaços de decisão para tentar impedir os avanços de tudo o que para eles fosse considerado pecado mediante a interpretação literal que fazem da Bíblia.

Embora antes da década de 1980 houvessem poucos parlamentares evangélicos eleitos, nenhum deles pertencia ao segmento pentecostal (Machado; Burity, 2014). Já no ano de 1986, os neopentecostais da IURD conseguiram eleger 18 parlamentares pentecostais para o Congresso Nacional (Mafra, 2001). Atualmente, segundo um levantamento preliminar do DIAP $^{53}$, a bancada evangélica possui 84 deputados, eleitos ou reeleitos, no ano de 2018. Em 2014, o DIAP identificou 75 deputados, e em 2010 a bancada iniciou os trabalhos legislativos

52 Entendemos como evangélicos tradicionais o segmento de fiéis que, segundo Vital da Cunha et al (2017), interpretam a Bíblia sem contextualizá-la com dias atuais. Em contra partida, consideramos, também em concordância com Vital da Cunha et al (2017) que os evangélicos progressistas são aqueles que leem e compreendem a escritura sagrada diante de uma perspectiva contemporânea.

53 Disponível em: http://www.diap.org.br/index.php/noticias/noticias/28532-eleicoes-2018-bancada-evangelicacrescena-camara-e-no-senado 
com 73 representantes. A bancada evangélica está registrada na Casa como Frente Parlamentar Evangélica, desde o ano de 2003, e recentemente foi renomeada como Frente Parlamentar Evangélica do Congresso Nacional.

É importante destacar que a confissão religiosa dos candidatos é valorizada por $40 \%$ dos fiéis no meio evangélico e chega a atingir índices maiores que 50\% dentre os fiéis da IURD (Machado, 2014). Dentro da lógica evangélica, votar em um candidato que defenda os princípios tradicionais cristãos nos espaços de decisão de poder não é somente exercer sua cidadania, mas, sobretudo, fazer sua parte contribuindo para a vitória de uma batalha considerada por eles como espiritual. Nas palavras de Machado:

\begin{abstract}
Quando os membros da igreja votam em seus candidatos, eles têm consciência de que não estão votando em uma pessoa, estão votando nas ideias defendidas pela igreja (...) os discursos apresentam a política como via para a implementação de uma hegemonia evangélica na medida em que o segmento confessional em questão for crescendo (...) é preciso formar cidadãos mais ativos e uma liderança política que possa ocupar os espaços de poder, propor leis e políticas públicas condizentes com o ideário cristão (Machado, 2014:11).
\end{abstract}

Ou seja, em concordância com a autora, notamos que o habitus religioso tornou-se gerador e orientador da visão que os fiéis têm sobre política (Bourdieu, 2008). Além disso, identificamos que o conservadorismo evangélico fortalece posturas tradicionais na arena pública brasileira (Cunha, 2017). Inclusive, em nosso campo, começamos a perceber ${ }^{54}$ que pessoas que deixavam comentários ofensivos nas páginas das Feministas Evangélicas apoiavam a eleição do então candidato Jair Bolsonaro à presidência da república. A partir das problematizações apresentadas por Cunha (2017) e Vital da Cunha et al (2017), constatamos que essas pessoas apoiaram Bolsonaro porque as ideias defendidas por ele estavam em consonância com o ideário religiosos dos evangélicos tradicionais.

Porém, as Feministas Evangélicas se posicionaram contra o candidato. Embora, durante sua campanha eleitoral defendesse a família, Bolsonaro também professava palavras de ódio em relação às minorias, às mulheres, aos negros, pobres e defendia o uso de armas de fogo. Por conta do discurso discrepante e bélico, as feministas evangélicas não conseguiram conceber como os evangélicos puderam compactuar e apoiar o candidato. Nota-se, portanto, que polarização entre evangélicos progressistas e evangélicos conservadores/tradicionais extrapolava concepções exclusivamente religiosas.

54 Tal percepção deu-se porque tais pessoas utilizam filtros em suas fotos de perfil - na rede social Facebook para demonstrar apoio ao então candidato à presidência da república, Jair Bolsonaro. 


\section{Conclusão}

Como aponta Rosado-Nunes (2017), nem sempre a religião funciona como força normatizadora. Ela também pode operar como força mobilizadora de resistência. Ou seja, é possível que as mulheres exerçam um contra poder frente às lideranças religiosas. Para Roese (2015), inclusive, a apropriação da religião pelas mulheres é o grande protagonismo feminino no século XXI. Em concordância com a autora, identificamos a manifestação contra a ordem vigente quando encontramos em nosso objeto em plena atuação na Internet. Embora arbitrariamente emudecidas e censuradas nos espaços eclesiais, as Feministas Evangélicas fazem uso dos ambientes virtuais para quebrarem o silêncio.

A partir da ótica de Gohn (2011), que concebe os movimentos sociais como grupos que se organizam a partir de uma causa coletiva, vislumbrando promover reconhecimento e transformações culturais a partir de relações de conflito com a sociedade, classificamos o Projeto Redomas, as Evangélicas pela Igualdade de Gênero, a Frente evangélica pela Legalização do aborto e as mulheres do Grupo Feministas Cristãs como coletivos que são parte integrante do movimento social feminista. O foco de sua luta é: a) acolher mulheres violentadas tanto na esfera doméstica quanto na esfera religiosa e/ou as que recorreram a prática do aborto inseguro; b) instrumentalizá-las para identificarem práticas abusivas e efetuar denúncias, se assim desejarem.

Ao descortinarem as violências cometidas e acobertadas no meio religioso, as Feministas Evangélicas foram capazes de perceber a magnitude dos problemas enfrentados pelas mulheres no meio cristão e identificaram a dominação simbólica estabelecida sobre elas por conta do acesso que tiveram à escolarização. Ou seja, a aquisição do ensino superior foi o principal fator para a desconstrução da concepção dos tradicionais papéis de gênero e do sentimento de culpa implantada pela religião. Por isso, as classificamos como uma elite intelectual que se coloca na esfera religiosa como defensora dos direitos femininos e tradutora das teorias feministas para a linguagem feminina popular que objetiva instruir as mulheres a identificar e combater a violência de gênero dentro dos espaços religiosos e domésticos.

Também é importante recapitular que no entendimento das Feministas Evangélicas, a descriminalização do aborto é uma questão de saúde pública e de cuidado/preservação das vidas femininas. Entretanto, vimos o quanto a violência doméstica e as discussões a respeito da legalização do aborto são os assuntos difíceis de serem debatidos e resolvidos por conta do ethos familista que os evangélicos conservadores/tradicionais possuem. Pelo fato da religião ser uma autoridade socializadora, para nós, é imprescindível a responsabilização da igreja e a 
necessidade de mudança de discurso como um fator determinante para o combate da violência de gênero. Compreendemos que a partir da mudança de discurso e de práticas punitivas para agressores, é possível promover a desconstrução da agressividade e do domínio masculino, assim como incentivar a construção de novas identidades orientadas à construção do respeito e da autoestima feminina.

No que diz respeito à utilização da Internet pelas Feministas Evangélicas como meio de enunciação, percebemos que a militância virtual não é capaz de desconstruir preconceitos e mudar concepções de indivíduos com pensamentos religiosos tradicionais. A despeito disso, é uma significante ferramenta para construção da visibilidade do grupo no que tange à luta por reconhecimento.

Esperamos ter contribuído para a desconstrução da imagem estereotipada que o senso comum concebeu em relação às mulheres evangélicas ao mostrar que há no meio religioso pessoas de racionalidade progressista que lutam pela defesa dos direitos das minorias, sobretudo se posicionando contra a utilização da política como um recurso para impor preceitos e práticas religiosas à coletividade. Por fim, sugerimos que novas pesquisas que contemplem a luta e a representatividade feminina em outras religiões serão de grande estima para toda a sociedade, visto que religiões que têm sua construção em bases patriarcais provê aos homens instrumentos para a dominação feminina. Ou seja, alertamos que violências vivenciadas pelas evangélicas podem ser experienciadas por mulheres que professam outra fé, pois o sistema religioso se constituiu como opressor ao controlar as mentes e os corpos femininos a partir - principalmente - da dominação simbólica.

\section{Referências}

BECKER, Howard S (2008), Outsiders: estudos de sociologia do desvio. Rio de Janeiro, Jorge Zahar.

BOURDIEU, Pierre (1998), "Sobre o poder simbólico", in P. Bourdieu, O poder simbólico. Rio de Janeiro, Bertrand Brasil, pp. 7-16. . (1998), "A identidade e a representação", in P. Bourdieu, O poder simbólico. Rio de Janeiro, Bertrand Brasil, pp.107-132. . (2012), A dominação masculina. Rio de Janeiro, Bertrand Brasil.

CASTELLS, Manuel (2013), Redes de indignação e esperança: movimentos sociais na era da internet. Rio de Janeiro, Zahar.

CUNHA, Magali do Nascimento (2017), "É preciso salvar a família": gênero, religião e política no contexto do neoconservadorismo evangélico nas mídias no Brasil, in C. V. Cunha; P. V. L. Lopes; J. Lul (Orgs.), Religião e Política: medos sociais, extremismo religioso e as eleições 2014. Rio de Janeiro, Fundação Heinrich Böll, Instituto de Estudos da Religião, pp. 157-169. 
DA MATTA, Roberto (1978), "O oficio de etnólogo, ou como ter anthropological blues". Boletim do Museu Nacional: Antropologia, n. 27, pp. 1-12 [Consult. 07-11-2020]. Disponível em http://www.ppgasmn-ufrj.com/uploads/2/7/2/8/27281669/boletim_do_museu_nacional_27.pdf

DINIZ, Debora; MEDEIROS, Marcelo; MADEIRO, Alberto (2017), "Pesquisa Nacional de Aborto 2016". Ciência saúde coletiva, v. 22, n. 2, pp. 653-660 [Consult. 07-11-2020]. Disponível em https://www.scielo.br/pdf/csc/v22n2/1413-8123-csc-22-02-0653.pdf

DUARTE, Rosália, (2002), "Pesquisa qualitativa: Reflexões sobre o trabalho de campo". Cadernos de Pesquisa, n. 115, pp. 139-154 [Consult. 07-11-2020]. Disponível em https://www.scielo.br/pdf/cp/n115/a05n115.pdf

GIDDENS, Anthony (2002), Modernidade e identidade. Rio de Janeiro, Jorge Zahar Editor. 128. (2004), "Gênero e Sexualidade", in A. Giddens, Sociologia. Porto Alegre, Artmed, pp. 102-

GOHN, Maria da Glória (2011), "Movimentos Sociais na contemporaneidade". Revista Brasileira de Educação, v. 16, n. 47, pp. 333-361 [Consult. 07-11-2020]. Disponível em https://www.scielo.br/pdf/rbedu/v16n47/v16n47a05.pdf

. (2017), Manifestações e protestos no Brasil: correntes e contracorrentes na atualidade. São Paulo, Cortez.

JACOB, Cesar R.; HESS, Dora R.; WANIEZ, Philippe; BRUSTLEIN, Violette (2003), Atlas da filiação religiosa e indicadores sociais no Brasil. Rio de Janeiro, Ed. PUC-Rio, São Paulo, Loyola.

LEMOS, Andre; LÉVY, Pierre (2010), "O Futuro da Internet: em direção a uma ciberdemocracia planetária. São Paulo, Paulus.

MACHADO, Maria das Dores Campos (2005), Representações e relações de gênero nos grupos pentecostais. Estudos Feministas, Florianópolis, v. 13, n. 2, pp. 387-396 [Consult. 07-11-2020]. Disponível em https://www.scielo.br/pdf/ref/v13n2/26891.pdf

MACHADO, Maria das Dores Campos; BARROS, Myriam Lins (2009), "Gênero, geração e classe: uma discussão sobre as mulheres das camadas médias e populares do Rio de Janeiro". Estudos Feministas, Florianópolis, v. 17, n. 2, pp. 369-393 [Consult. 07-01-2020]. Disponível em https://www.scielo.br/pdf/ref/v17n2/05.pdf

MACHADO, Maria das Dores; BURITY, Joanildo (2014), “A ascensão Política dos Pentecostais no Brasil na Avaliação de Líderes Religiosos”. DADOS, v. 57, n. 3, pp. 601-631 [Consult. 07-112020]. Disponível em https://www.scielo.br/pdf/dados/v57n3/0011-5258-dados-57-03-0601.pdf

MAFRA, Clara (2001), Os Evangélicos. Rio de Janeiro, Jorge Zahar.

MENDONÇA, Antonio Gouvêa (2005), "O protestantismo no Brasil e suas encruzilhadas". Revista USP, São Paulo, n. 67, pp. 48-67 [Consult. 07-11-2020]. Disponível em https://www.revistas.usp.br/revusp/article/view/13455

. (2007), "Protestantismo no Brasil: Um caso de religião e cultura". Revista USP, n. 74, pp. 160-173. Disponível em https://www.revistas.usp.br/revusp/article/view/13610 [Consult. 07-112020].

MARTINS, Milena Geisa dos Santos; GUEDES, Moema de Castro (2019), "Feminismo e religião: uma análise das feministas evangélicas na rede social". Sinais, v. 2, n. 23, pp. 58 -77 [Consult. 0711-2020]. Disponível em https://periodicos.ufes.br/sinais/article/view/24049 
MISKOLCI, Richard (2016), "Sociologia Digital: notas sobre pesquisa na era da conectividade". Revista Contemporânea, v. 6, n. 2, pp. 275-297 [Consult. 07-11-2020]. Disponível em http://www.contemporanea.ufscar.br/index.php/contemporanea/article/view/525/211

PEREZ, Olívia C.; SILVA FILHO, Alberto L. A. (2017), "Coletivos: um balanço da literatura sobre as novas formas de mobilização da sociedade civil". Latitude, v. 11, n. 1, pp. 255-94 [Consult. 07-112020]. Disponível em https://www.seer.ufal.br/index.php/latitude/article/view/2812

PROJETO REDOMAS, 2018. [Consult. 07/11/2020]. Disponível em http://projetoredomas.com/wpcontent/uploads/2018/07/cartilha-redomas.pdf

ROESE, Anete (2015), "Religião e feminismo descolonial: os protagonismos e os novos agenciamentos religiosos das mulheres no século XXI." Horizonte, v. 13, n. 39, pp. 1534-1558. Disponível em http://periodicos.pucminas.br/index.php/horizonte/article/view/P.21755841.2015v13n39p1534 [Consult. 07-11-2020].

ROSADO-NUNES, Maria José (2017), "Feminismo, gênero e religião - os desafios de um encontro possível". Estudos da Religião, v. 31, n. 2, pp. 65-76 [Consult. 07-11-2020] Disponível em https://www.metodista.br/revistas/revistas-ims/index.php/ER/article/view/7556/5959

ROSSINI, Patrícia Gonçalves da Conceição (2014), "Da rede para as ruas: mídias sociais como novas "armas" na luta por reconhecimento?". Comunicação \& Sociedade, v. 36, n. 1, pp. 301-325 [Consult. 07-11-2020]. Disponível em https://www.metodista.br/revistas/revistasims/index.php/CSO/article/view/4511/4404

SOUZA, Sandra Duarte de (2004), "Gênero e religião nos estudos feministas". Estudos Feministas, Florianópolis, v. 12, n. 9, pp. 122-130 [Consult. 07/11/2020]. Disponível em https://www.scielo.br/pdf/ref/v12nspe/a14v12ns.pdf

TEIXEIRA, M. Jacqueline (2014), "Mídia e performances de gênero na Igreja Universal: O desafio Godllywood". Religião. Sociedade [online], v. 34, n. 2, pp. 232-256 [Consult. 07-11-2020]. Disponível em https://www.scielo.br/pdf/rs/v34n2/0100-8587-rs-34-02-0232.pdf

VILHENA, C. Valéria (2009), Pela Voz das Mulheres: uma análise da violência doméstica entre mulheres evangélicas atendidas no Núcleo de Defesa e Convivência da Mulher - Casa Sofia. 2009. Dissertação (Mestrado em Ciências da Religião). Universidade Metodista de São Paulo, São Paulo. $152 \mathrm{p}$.

VITAL DA CUNHA, Christina; LOPES, Paulo Victor Leite; LUI, Janayna (2017), Religião e Política: medos sociais, extremismo religioso e as eleições 2014. Rio de Janeiro, Fundação Heinrich Böll e Instituto de Estudos da Religião

WOITOWICZ, Karina Janz (2012), "Imprensa feminista no contexto das lutas das mulheres: Ativismo midiático, cidadania e novas formas de resistência." Revista ação midiática - Estudos em Comunicação, Sociedade e Cultura, v. 2, n. 1, pp. 13-31[Consult. 07-11-2020]. Disponível em https://revistas.ufpr.br/acaomidiatica/article/view/27915/19299

WOODHEAD, Linda (2002), "Mulheres e gênero: uma estrutura teórica". Estudos da Religião, n. 1, pp. 1-11[Consult. 07/11/2020]. Disponível em https://www.pucsp.br/rever/rv1_2002/p_woodhe.pdf 


\begin{abstract}
This article aims to present, through interviews and netnography, collectives that emerge from the religious sphere, where dissonant voices do not agree with the female subjugation implemented by religion who denounces in virtual environments the violence against women in environments domestic or ecclesial. Besides volunteer work, instructing, and supporting victims of violence, the Evangelical Feminists group fight for abortion legalization, as they understand it as a public health issue. However, even when fighting for women's rights, they are threatened by individuals who have a familist ethos and a conservative worldview because they understand that they want to destroy the family.
\end{abstract}

Keywords: Feminism; religion; gender violence; policy.

\title{
Resumen
}

Nuestro objetivo en este artículo, a partir de entrevistas y netnografía, es mostrar que desde el ámbito religioso surgen colectivos cuyas voces disonantes no concuerdan con la subyugación femenina implementada por la religión y denuncian en entornos virtuales la violencia practicada contra las mujeres en los ambientes doméstico y/o eclesial. Además de trabajar voluntariamente en la instrucción y acogida de víctimas de violencia, es importante destacar que las Feministas Evangélicas que hemos investigado luchan por la legalización del aborto, pues entienden que este es un tema de salud pública. Sin embargo, incluso cuando luchan por los derechos de las mujeres, son amenazadas por individuos que tienen un espíritu familista y una cosmovisión conservadora porque entienden que quieren destruir a la familia.

Palabras clave: Feminismo; religión; violencia de género; política. 